\title{
Acute myocardial infarction in patient without cardiac risk factors during emergence from general anesthesia: a case report
}

\author{
Thu Nguyen Dang ${ }^{*}$ D, Nam Tran Hoai, Son Nguyen Viet, Tri Le Huu, Khuong Truong Van, Cuong Nguyen Manh \\ and Tiep Tran Dac
}

\begin{abstract}
Background: Perioperative myocardial infarction is a rare but highly fatal complication, which often occurs in patients with poor preoperative cardiac conditions undergoing high-risk surgery. We report a case of acute myocardial infarction in a patient without cardiac risk factors during emergence from general anesthesia for removal of spinal screws.

Case presentation: A 37-year-old, $60 \mathrm{~kg}$, and $160 \mathrm{~cm}$ man, who had no history of cardiovascular diseases, underwent removal of loosen spinal plug screws at L4-L5. The preoperative investigations revealed no abnormality and the patient was ASA I. The surgery was uneventful. During aspiration of the endotracheal tube, the patient suddenly experienced paroxysmal atrial fibrillation and ST segment elevation in DII lead. He was treated with oxygenation, optimal hemodynamics, minimize cardiac work, antiarrhythmias, and anticoagulation. The clinical conditions improved. Sinus rhythm was regained after $24 \mathrm{~h}$ and discharged without complications.

Conclusions: Myocardial infarction can occur suddenly and unexpectedly in patients without risk factors after a low-risk surgery in any period of general anesthesia. Close monitoring and prompt treatment with this condition is important for improving outcomes.
\end{abstract}

Keywords: Perioperative myocardial infarction, Non-cardiac risk factors, General anesthesia

\section{Background}

Perioperative myocardial infarction (MI) is rare but associated with high mortality and morbidity $(1.5-42 \%)$ [1]. It is an emergency and anesthetic challenge, which often occurs in patients with poor preoperative cardiac conditions undergoing high-risk surgery [2]. We report a case of acute MI in a patient without cardiac risk factors during emergence from general anesthesia for surgical removal of spinal screws.

\footnotetext{
* Correspondence: nguyendangthu@vmmu.edu.vn

Department of Anesthesia, Military Hospital 103, Vietnam Military Medical University, 261 Phung Hung Street, Ha Dong District, Hanoi, Vietnam
}

\section{Case presentation}

A 37 -year-old, $60 \mathrm{~kg}$, and $160 \mathrm{~cm}$ man was diagnosed with loosening of fixation screws to L4-L5 and scheduled for surgical removal under general anesthesia. He was otherwise well, without history of cardiovascular disease, diabetes, dyslipidemia, smoking, or chest pain. The last general anesthesia for screw implantation procedure was uneventful. Preoperative electrocardiography (ECG) showed normal sinus rhythm and no sign of myocardial ischemia (Fig. 1); chest X-ray was unremarkable; blood tests showed hemoglobin $14.7 \mathrm{~g} / \mathrm{dL}$ and hematocrit 43.8\%; and other laboratory findings were within normal ranges except for slightly elevation of aspartate

\section{Springer Open}

(c) The Author(s). 2020 Open Access This article is licensed under a Creative Commons Attribution 4.0 International License, which permits use, sharing, adaptation, distribution and reproduction in any medium or format, as long as you give appropriate credit to the original author(s) and the source, provide a link to the Creative Commons licence, and indicate if changes were made. The images or other third party material in this article are included in the article's Creative Commons licence, unless indicated otherwise in a credit line to the material. If material is not included in the article's Creative Commons licence and your intended use is not permitted by statutory regulation or exceeds the permitted use, you will need to obtain permission directly from the copyright holder. To view a copy of this licence, visit http://creativecommons.org/licenses/by/4.0/. 

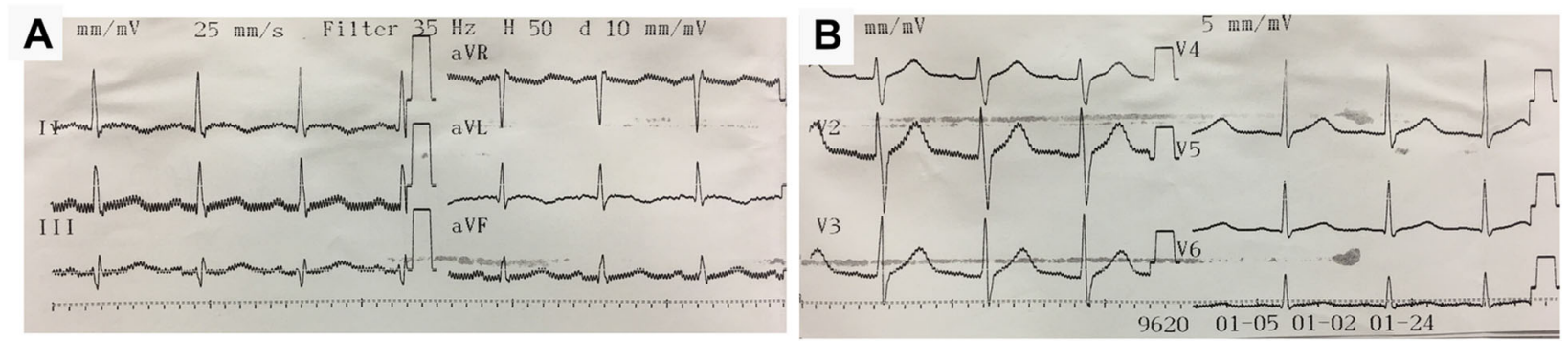

Fig. 1 Preoperative 12-lead ECG of the patient: a DI-DIII, aVR, aVL, and aVF lead; $\mathbf{b}$ V1-V6 lead showed normal sinus rhythm and no sign of myocardial ischemia with HR 91 bpm, PR 156 ms, QRS 102 ms, and QT/QTc 398/446 ms

aminotransferase $(51 \mathrm{IU} / \mathrm{L})$. The patient was American Society of Anaesthesiologists' (ASA) classification I.

The patient was monitored during anesthesia, using ECG, saturation of peripheral oxygen $\left(\mathrm{SpO}_{2}\right)$, and noninvasive arterial blood pressure. Preoperative blood pressure (BP) was $130 / 87 \mathrm{mmHg}$, heart rate $(\mathrm{HR}) 75 \mathrm{bpm}$, body temperature $36.1{ }^{\circ} \mathrm{C}$, and $\mathrm{SpO}_{2}$ 98\%. General anesthesia was induced and maintained with fentanyl (total $350 \mu \mathrm{g}$ ), propofol $120 \mathrm{mg}$, rocuronium $50 \mathrm{mg}$, and sevoflurane $(1.5-2.5 \%)$. The surgery went uneventfully throughout the whole of $60 \mathrm{~min}$ of operation, with the patient on prone position, estimated blood loss of 100 $\mathrm{mL}$, and without any complications. No significant changes in respiratory, cardiovascular, or neurological parameters was noted through the surgery.

Upon completion of the surgery, the patient was changed to the supine position. Ten minutes after discontinuation of sevoflurane, the patient was awake with $\mathrm{HR}$ $86 \mathrm{bpm}$, BP $135 / 85 \mathrm{mmHg}, \mathrm{SpO}_{2} 100 \%$ on spontaneous breathing, and ready for extubation. During endotracheal tube (ETT) aspiration, ECG suddenly changed with paroxysmal atrial fibrillation (AF) and fast ventricular response (HR 170-180 bpm), ST segment elevation (0.4$0.5 \mathrm{mV}, \max 0.6 \mathrm{mV}$ ), and BP decreased to $105 / 54$ $\mathrm{mmHg}$. Immediate setup of invasive hemodynamic monitoring lines showed arterial pressure of $85 / 40 \mathrm{mmHg}$ and central venous pressure of $8 \mathrm{mmHg}$.

The patient was immediately sedated and mechanically ventilated with midazolam and fentanyl. Intravenous heparin (bolus of $4000 \mathrm{IU}$, then infusion at $600 \mathrm{IU} / \mathrm{h}$ ) and amiodarone (bolus $150 \mathrm{mg}$, then infusion at $5 \mathrm{mg} /$ $\mathrm{kg} / \mathrm{h}$ ) were given. Noradrenaline $0.03-0.1 \mu \mathrm{g} / \mathrm{kg} / \mathrm{min}$ was infused to maintain the mean arterial pressure (MAP) of 60-70 mmHg. Transthoracic echocardiography (TTE) showed normal left ventricular wall motion and dimension (LVEDd $41 \mathrm{~mm}$ ), with left ventricular ejection fraction of $57 \%$. There was no right ventricular strain, pericardial effusion, or other pathology. 12-Lead ECG at
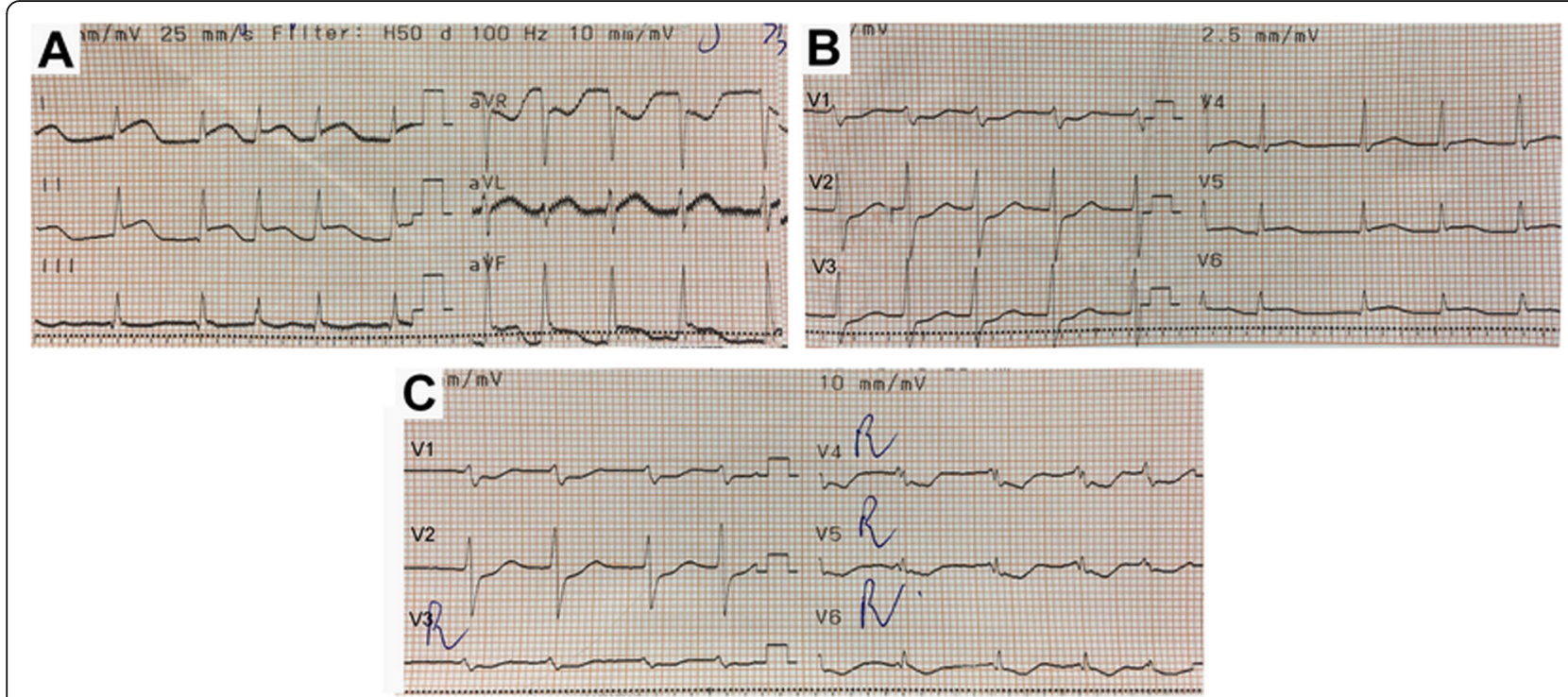

Fig. 2 12-Lead ECG at 10 min after onset of ST elevation: a DI-DIII, aVR, aVL, and aVF lead; b V1-V6 lead; c V1, V2, and right precordial leads $\left(V_{3} R\right.$, $V_{4} R, V_{5} R$, and $V_{6} R$ ) showed $S T$ elevation in DI, DII, aVF, and ST depression in V1, V2, aVR, and right precordial leads 
10 min after onset of ST elevation showed AF, ST elevation in DI, DII, aVF, and ST depression in V1, V2, aVR, and right precordial $\left(V_{3} R, V_{4} R, V_{5} R\right.$, and $\left.V_{6} R\right)$ leads (Fig. 2). Arterial blood gas analysis showed mild metabolic acidosis (pH 7.38; $\mathrm{PaCO}_{2} 30 \mathrm{mmHg} ; \mathrm{HCO}_{3}-18 \mathrm{mmol} / \mathrm{L} ; \mathrm{BE}-6$ $\mathrm{mmol} / \mathrm{L}$ ), normal serum electrolytes.

Tachycardia persisted with elevated ST segment during $10 \mathrm{~min}$. Subsequently, HR- and ST-segment elevation gradually decreased (Table 1), and the noradrenaline dose was also slowly decreased.

After $4 \mathrm{~h}$ in the operating room, the patient was hemodynamically stable without noradrenaline. He was back on spontaneous breathing and transferred to the intensive care unit (ICU). Extubation was performed several hours later. Subsequent laboratory investigations showed elevation of Troponin-I and creatine kinase MB (CK-MB) levels (Table 2). Computed tomography coronary angiography showed the stenosis in the middle left anterior descending (LAD) (50\%) and the middle circumflex coronary artery (LCx) (50\%) (Fig. 3). Repeated TTE in ICU showed no significant wall motion abnormality. The heart returned to sinus rhythm, and HR and MAP were within normal limits after $24 \mathrm{~h}$. The patient remained stable with normal sinus rhythm, chest painfree, and downtrend in troponin-I and CK-MB levels. The patient was bridged to dual antiplatelet therapy with clopidogrel $75 \mathrm{mg}$ and aspirin $100 \mathrm{mg}$ daily. He was transferred to a general ward after 7 days in ICU and discharged on dual antiplatelet therapy at postoperative day 10 without any complications.

\section{Discussion}

Myocardial infarction is defined as an irreversible necrotic state of myocardium [3]. Most commonly ST elevation MI caused by an acute occlusion of a coronary blood vessel secondary to acute plaque rupture, thrombosis, or coronary artery vasospasm [3]. Perioperative MI often occurs in patients with poor preoperative cardiac conditions, such as advanced ages, smoking, hypertension, obesity, high cholesterol, diabetes mellitus, or family history of coronary artery disease [2, 4]. However, it may suddenly happen in a young patient without noticeable premedical history of coronary artery disease during emergence from general anesthesia for a relatively short and uneventful surgery. No known risk
Table 2 Myocardial biomarkers change after the onset of ST elevation

\begin{tabular}{lllllll}
\hline & $30 \mathrm{~min}$ & $4 \mathrm{~h}$ & $7 \mathrm{~h}$ & $18 \mathrm{~h}$ & $34 \mathrm{~h}$ & $54 \mathrm{~h}$ \\
\hline Troponin - I (pg/ml) & $<10$ & 1723.8 & 2631.1 & 3602.9 & 1399.2 & 627.7 \\
CK-MB (IU/l) & 21 & 32.9 & 38.6 & 35.8 & 25.8 & 118.2 \\
\hline
\end{tabular}

Normal range: Troponin - I (0.0-35 pg/ml); CK-MB (0-24 IU/I). CK-MB creatine kinase MB

factor of coronary artery disease was reported in our patient. His pre-and intraoperative ECG did not show any sign of myocardial ischemia. Of note, invasive coronary artery imaging techniques were not indicated for this patient due to his young age and chest pain-free.

According to the Third Universal Definition of MI, acute MI is diagnosed based on the rise of cardiac biomarkers and at least one of the following criteria: symptoms of ischemia, ECG changes, changes on an echocardiography, or evidenced by angiography/autopsy [3]. Our patient was diagnosed of MI due to a significant elevation of Troponin I and CK-MB levels (Table 2) and new significant ST changes. In the settings of general anesthesia, ECG changes could be the only early sign of ischemia [3]. As such, close monitoring of ECG and hemodynamics is important to recognize MI during emergence from general anesthesia. While waiting for further investigations to confirm MI, prompt treatment should be initiated if MI is suspected [5]. Oxygenation, hemodynamic optimization, anti-arrhythmias, anticoagulation, coronary vasodilation, and mechanical ventilation to minimize myocardial oxygen consumption should be considered wherever appropriate $[6,7]$. Coronary revascularization may be necessary if there is significant coronary stenosis. Since moderate stenosis of LAD (50\%) and LCx (50\%) were only lesions found in this patient, his acute MI could be associated with coronary vasospasm [8].

Coronary artery spasm could result from the interaction of vasoconstrictor stimuli and underlying abnormality of a coronary artery (endothelial dysfunction or a primary hyperreactivity of vascular smooth muscle cells), the causes of which is still unlear [9]. Potential general mechanisms to explain the occurrence of coronary vasospasm include redistribution of blood flow, altered humoral factors, increased catecholamine, and imbalance of vasoconstrictor-vasodilator forces. ETT

Table 1 Hemodynamic parameters and ECG change after the onset of ST elevation

\begin{tabular}{llllllll}
\hline & $10 \mathrm{~min}$ & $30 \mathrm{~min}$ & $1 \mathrm{~h}$ & $4 \mathrm{~h}$ & $16 \mathrm{~h}$ & $24 \mathrm{~h}$ & $48 \mathrm{~h}$ \\
\hline Heart rhythm & AF & AF & AF & AF & AF & Sinus rhythm & Sinus rhythm \\
Heart rate (bpm) & $160-170$ & $120-130$ & $90-100$ & $90-100$ & $90-100$ & $80-90$ & $70-80$ \\
Blood pressure & $105 / 50$ & $110 / 55$ & $115 / 54$ & $135 / 80$ & $130 / 75$ & $135 / 80$ & $125 / 70$ \\
ST elevation DII (mV) & $0.4-0.5$ & $0.2-0.3$ & $0.1-0.2$ & $<0.1$ & $<0.1$ & $<0.1$ & $<0.1$ \\
\hline
\end{tabular}

Trends in heart rhythm, heart rate blood pressure, and ST elevation of the patient after onset of ST elevation. AF atrial fibrillation 

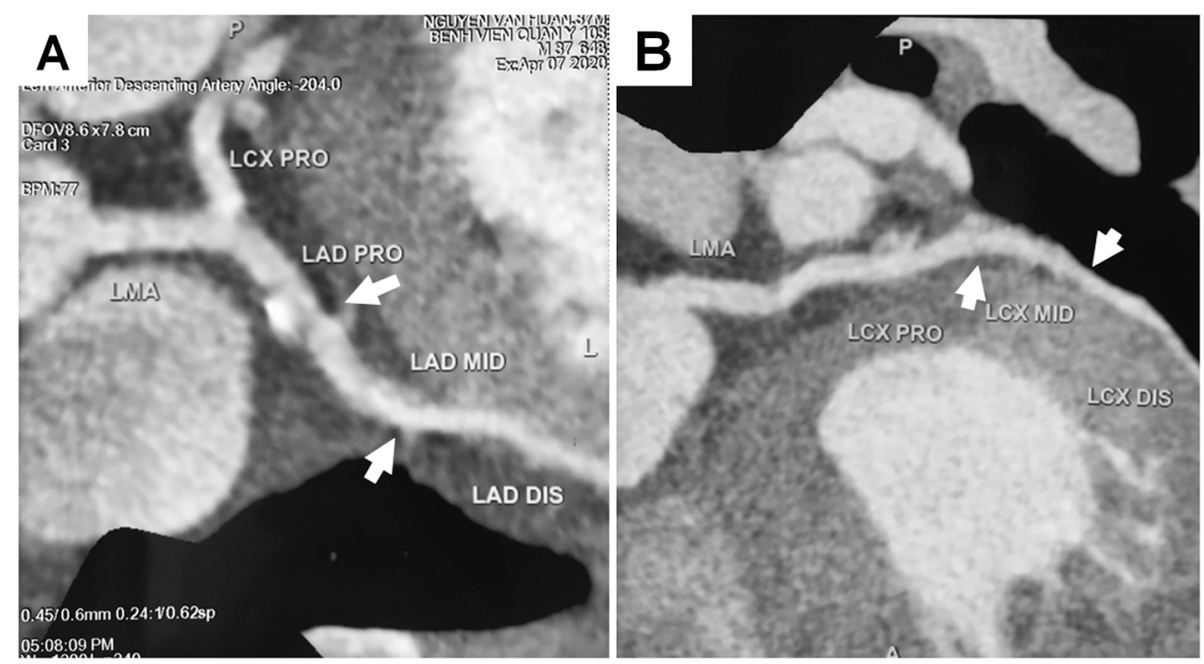

Fig. 3 Postoperative CT coronary angiogram. Mild stenosis was noted at the middle left anterior descending coronary artery (LAD) (50\%) and middle left circumflex coronary artery (LCX) (50\%). LMA left main artery, PRO proximal, MID mild, DIS distal

aspiration causes stimulation of the vagus nerve and release of acetylcholine, which in turn cause release of norepinephrine from the postganglionic sympathetic nerve terminals in the heart, leading to excess stimulation adrenergic system [10]. Since large coronary arteries are innervated predominantly with alpha (vasoconstrictor) adrenergic receptors. ETT stimulation may trigger significant coronary vasoconstrictor. The other factors during emergence from general anesthesia, including pain, hypoxia, and inflammation, may increase the sensitivity of the coronary arteries to those stimuli.

Perioperative MI may be complicated with various types of arrhythmia, including AF (6-21\%) [11] or even life-threatening ventricular arrhythmias. Arrhythmias, if not timely identified and treated, may worsen hemodynamic consequences caused by MI. Therefore, close monitoring of ECG and appropriate response to arrhythmias are required all period of general anesthesia to reduce mortality and morbility.

\section{Conclusions}

Myocardial infarction can occur suddenly and unexpectedly in patient without risk factors after a low-risk surgery in any period of general anesthesia. Close monitoring of hemodynamics and ECG is very important for early diagnosis of this condition. If acute MI is suspected, prompt diagnosis and management may limit damages to myocardium and improve outcomes.

\section{Abbreviations}

ASA: American Society of Anesthesiologists Classification; MI: Myocardial infarction; ECG: Electrocardiography; SpO2: Saturation of peripheral oxygen; BP: Blood pressure; HR: Heart rate; ETT: Endotracheal tube; AF: Atrial fibrillation; CVP: Central venous pressure; MAP: Mean arterial pressure; TTE: Transthoracic echocardiography; LVEDd: Left ventricular end-diastolic diameter; CK-MB: Creatine kinase MB; LAD: Left anterior descending artery; LCX: Circumflex coronary artery; ICU: Intensive care unit

\section{Acknowledgements \\ None}

\section{Authors' contributions}

TND and TTD participated in the anesthetic management. TND collected the patient data and drafted the manuscript. NTH, SNV, TLH, KTV, and CNM revised the manuscript. The authors read and approved the final manuscript.

\section{Funding}

Not applicable.

\section{Availability of data and materials}

Data relevant to this case report are not available for public access because of patient privacy concerns but are available from the corresponding author on reasonable request.

Ethics approval and consent to participate Not applicable

\section{Consent for publication}

We had obtained the consent to publish from the patient.

\section{Competing interests}

The authors declare that they have no competing interests.

Received: 18 May 2020 Accepted: 4 June 2020

Published online: 16 June 2020

\section{References}

1. Landesberg G, Beattie WS, Mosseri M, Jaffe AS, Alpert JS. Perioperative myocardial infarction. Circulation. 2009;119(22):2936-44.

2. Sellers D, Srinivas C, Djaiani G. Cardiovascular complications after noncardiac surgery. Anaesthesia. 2018;73(Suppl 1):34-42.

3. Thygesen K, Alpert JS, Jaffe AS, Simoons ML, Chaitman BR, White HD, et al. Third universal definition of myocardial infarction. Eur Heart J. 2012;33(20): 2551-67.

4. Toyama H, Saito K, Anzai H, Kobayashi N, Aihara T, Ejima Y, et al. A case of myocardial infarction caused by obstruction of a drug-eluting stent during the perioperative period. JA Clinical Reports. 2015;1(1):22.

5. Kristensen SD, Knuuti J, Saraste A, Anker S, Botker HE, Hert SD, et al. 2014 ESC/ESA Guidelines on non-cardiac surgery: cardiovascular assessment and management: The Joint Task Force on non-cardiac surgery: cardiovascular 
assessment and management of the European Society of Cardiology (ESC) and the European Society of Anaesthesiology (ESA). Eur Heart J. 2014;35(35): 2383-431.

6. Ibanez B, James S, Agewall S, Antunes MJ, Bucciarelli-Ducci C, Bueno H, et al. 2017 ESC Guidelines for the management of acute myocardial infarction in patients presenting with ST-segment elevation: The Task Force for the management of acute myocardial infarction in patients presenting with ST-segment elevation of the European Society of Cardiology (ESC). Eur Heart J. 2018;39(2):119-77.

7. Reddy K, Khaliq A, Henning RJ. Recent advances in the diagnosis and treatment of acute myocardial infarction. World J Cardiol. 2015;7(5):243-76.

8. Sidi A, Dahleen L, Gaspardone A. Coronary vasospasm during anesthesia induction: awareness, recognition, possible mechanisms, anesthetic factors, and treatment. J Clin Anesth. 2008;20(1):64-9.

9. Yasue $\mathrm{H}$, Nakagawa $\mathrm{H}$, Itoh T, Harada E, Mizuno Y. Coronary artery spasm — clinical features, diagnosis, pathogenesis, and treatment. Journal of Cardiology. 2008;51(1):2-17.

10. Yasue H, Touyama M, Shimamoto M, Kato H, Tanaka S. Role of autonomic nervous system in the pathogenesis of Prinzmetal's variant form of angina. Circulation. 1974;50(3):534-9.

11. Gorenek B, Blomstrom Lundqvist C, Brugada Terradellas J, Camm AJ, Hindricks G, Huber K, et al. Cardiac arrhythmias in acute coronary syndromes: position paper from the joint EHRA, ACCA, and EAPCI task force. Euro Intervention. 2015;10(9):1095-108.

\section{Publisher's Note}

Springer Nature remains neutral with regard to jurisdictional claims in published maps and institutional affiliations.

\section{Submit your manuscript to a SpringerOpen ${ }^{\circ}$ journal and benefit from:}

- Convenient online submission

- Rigorous peer review

- Open access: articles freely available online

- High visibility within the field

- Retaining the copyright to your article 